\title{
Charging Property and Charge Trap Parameters in Porous Polypropylene Film Using Thermally Stimulated Current
}

\author{
Fukuzo Yoshida and Masahiko Yoshiura \\ Osaka Institute of Technology Osaka, \\ Japan
}

\section{Introduction}

The polymeric materials are utilized in industry and an ordinary household with the characteristic that a natural organic material does not have. Research and development are performed actively now because the polymers are materials with a variety of functionality (Imai et al., 2002; Ishii et al., 2009; Ishimoto et al., 2009; Varlow \& Li, 2002). By such a background, we aimed at the polymer system piezoelectric material which let it give piezoelectricity as the sensor function. For typical piezoelectric material(Koga \& Ohigashi,1985;Lindner etal.,2002), $\mathrm{PZT}$ and $\mathrm{BaTiO}_{3}$ are well known until now. In contract, the PVDF of the polymer system piezoelectric material immobilized $\mathrm{CF}_{2}$ dipolar orientation. Piezoelectric modulus $d_{33}$ of the porous polymer electrets is higher than PVDF, and in a polymer system, polaristation reversal happens.

However, the electrical conduction mechanism of the porous polymer electrets(Cao et al.,1998;Xia et al.,1999) is complicated, and a study is gone ahead with as an important theme for the development. It has been considered that charge carrier traps in a substance play an important role in the charging phenomenon. For this theme, the thermally stimulated current (TSC)(Braünlich,1979;Chen \& Kirsh,1981;Ikezaki \& Hori,1998;Baba \& Ikezaki,1992;Ikezaki \& Murata,2006;Oka \& Ikezaki,1992;Perlman \& Creswell,1971;Yoshida et al.,1998) is one effective measurement. The TSC measurement activates a sample by corona discharge or light and gives a sample heat stimulation by constant heating rate and takes out electric charge in inside of sample to produce a current of the external circuit. This measurement is not a change of state other than a sample, and is extremely high sensitive measurement.

On the other hand, the surface boundary and charging phenomenon are complicated because the inner structure of the sample is not uniform. As a result, it is thought that the signal of the TSC spectrum which measured is a compounds of TSC spectra caused by several charge traps. We developed the evaluation method using the characteristic of the TSC measurement. This evaluation method separates plural TSC spectra precisely and evaluates the information of the trap precisely. As for this separation method (named AEM separation system), it is done computation process on Windows. Above all, an escape 
frequency factor proposed a directly ratable method (named AEM-v(Yoshida \& Maeta,1991)) for the first time even if a waveform condition of the TSC spectrum was bad.

Polymer system piezoelectric material to use for this study is porous polypropylene. The temperature characteristic of the surface charge electric potential was examined directly by the thermally stimulated charge decay (TSCD) other than TSC measurement.

In this study, it applied the AEM separation system which we proposed to the separation of the TSC spectrum and analyzed the property of the trap which imperforate polypropylene and porous polypropylene formed.

\section{Materials and methods}

An experiment sample is the polypropylene which is one of the four major general- purpose resin. It shows the different polypropylene (PP) of three kinds of properties in Table 1. A polypropylene film as prepared (PP1) and the polypropylene drawn film (PP2) to two axes (Futamura Chemicals) were used as base polymers. The porous film containing pores of several micro meters in radius prepared (PP3) was drawn to the thickness of $75 \mu \mathrm{m}$.

\begin{tabular}{c|c|c}
\hline sample name & type & Thickness $(\mu \mathrm{m})$ \\
\hline PP1 & solid & 50 \\
\hline PP2 & solid(drawn to two axis) & 50 \\
\hline PP3 & porous(drawn to two axis) & 75 \\
\hline
\end{tabular}

Table 1. Three PP films used in this experiment.

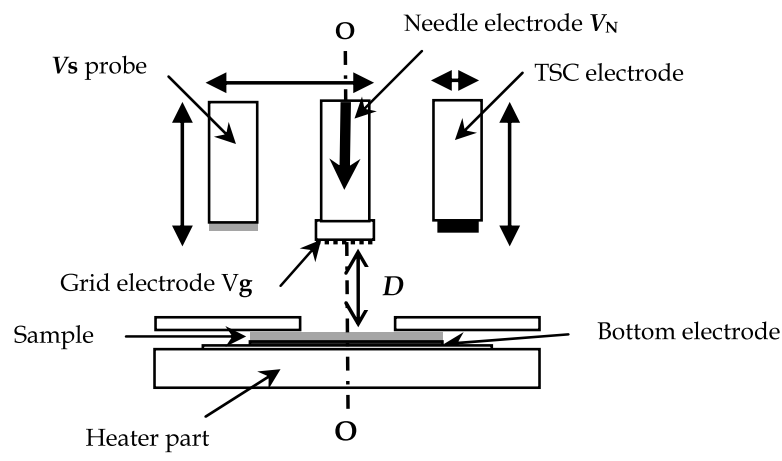

Fig. 1. Electrode arrangement for various measurements in the cryostat.

Figure 1 shows the electrode arrangement that various measurements are possible. The corona electrical charging of the sample removing was performed by a needle electrode to central axis $\mathrm{O}-\mathrm{O}$. The corona charge was carried out with voltage $V_{\mathrm{N}}$ of tungsten needle electrode fixed at $\pm 3 \mathrm{kV}$ and the grid voltage $V_{\mathrm{g}}$ at less than $\pm 2 \mathrm{kV}$ for $60 \mathrm{~s}$ at $1 \mathrm{~atm}$. The corona discharge was measured under constant humidity after pouring the dry gas of the fixed quantity. Surface potential $V_{\mathrm{s}}$ was measured with surface potential electrometer (Model 344, Trec Japan). The TSC measurement was performed by removing the TSC electrode to the central axis shown in Fig. 1 with a separation of $D=1 \mathrm{~mm}$ from the sample. 
The open TSC signal was measured under a vacuum using electrometer (Keithley 610C). As a result of having made shielding on an external circuit, it enabled very sensitive TSC measurement. The TSC observation temperature region reached in the range of $430 \mathrm{~K}$ from $250 \mathrm{~K}$ using $\mathrm{LN}_{2}$ cryostat.

Figure 2 shows diagram of the TSC measurement. This figure is an example applying bias electric field $\left(E_{\mathrm{b}}\right)$ for present temperature $\left(T_{\mathrm{b}}\right)$ and setting time $\left(t_{\mathrm{b}}\right)$. This experiment performed charge injection by corona electrical charging not bias electric field. The corona charging processed a sample in the polarity of each positive and negative. After one corona charging process, the TSC spectra were measured two times in succession. It calls the TSC spectrum "1st run TSC" and "2nd run TSC" sequentially. The TSCD measurement is the basically same as TSC. The upper part electrode which showed in Fig. 1 becomes the surface potential prove.



Fig. 2. Diagram of the TSC measurement

\section{TSC spectrum analysis}

AEM- $v$ is necessary for the construction on the AEM separation system which we are proposed.

\subsection{AEM theory}

AEM- $v$ is able to evaluate the escape frequency factor $v$ utilizing all the data of an object TSC spectrum. The advantageous property of this method is that both the $v$ and $E_{\mathrm{t}}$ value could be determined. The equation used in AEM- $v$ was derived from an equation of the TSC with constant heating rate $\beta$ under the condition of first-order slow retrapping is expressed as:

$$
I(T)=I_{o} \exp \left\{\frac{-E_{t}}{k T}-\frac{v}{\beta} \int_{T_{o}}^{T} \exp \left(\frac{-E_{t}}{k T}\right) \mathrm{d} T\right\}
$$


The following symbols are used : $I_{0}=n_{0} e \mu v \tau A E(\mathrm{~A}), n_{\mathrm{o}}$ : the carrier density of the filled traps at $t$ $=0\left(\mathrm{~m}^{-3}\right), e$ : the electric charge $(\mathrm{C}), \mu$ : the carrier mobility $\left(\mathrm{m}^{2} / \mathrm{V} \cdot \mathrm{s}\right), v$ : an escape frequency factor $\left(\mathrm{s}^{-1}\right), \tau$ : the life time of a free carrier $(\mathrm{s}), A$ : the area of the electrode $\left(\mathrm{m}^{2}\right), E$ : the applied electric field $(\mathrm{V} / \mathrm{m}), E_{\mathrm{t}}$ : energy depth of carrier trap $(\mathrm{eV}), k$ : the Boltzmann's constant $8.617 \times 10^{-5}$ $(\mathrm{eV} / \mathrm{K}), \beta$ : the heating rate $(\mathrm{K} / \mathrm{s}), \mathrm{T}$ : the absolute temperature $(\mathrm{K}), T_{\mathrm{o}}$ : the absolute temperature from which the heating begins after filling of the traps with carrier at the time $t$.

The theoretical TSC spectrum shown in Fig.3 was calculated by eq.(1) with a TSC maximum $m\left(T_{\mathrm{mo}}, I_{\mathrm{mo}}\right)$ and trap depth $E_{\mathrm{to}}$. The basic formula of AEM- $v$ becomes the eq.(2). The escape frequency factor $v$ is thus expressed by a ratio of $I_{a}$ to $I_{b}$ :

$$
v=\frac{\frac{\beta k}{E_{t}}\left\{\ln \frac{I_{a}}{I_{b}}+\frac{E_{t}}{k}\left(\frac{1}{T_{a}}-\frac{1}{T_{b}}\right)\right\}}{\sum_{n=0}(-1)^{n} \frac{(n+1) !}{\left(\frac{E_{t}}{k T_{b}}\right)^{n+2}} \exp \left(\frac{-E_{t}}{k T_{b}}\right)\left[1-\left(\frac{T_{a}}{T_{b}}\right)^{n+2} \exp \left\{\frac{-E_{t}}{k}\left(\frac{T_{a}-T_{b}}{T_{a} T_{b}}\right)\right\}\right]}
$$

The integral terms in eq. (1) were integrated by the asymptotic expansion series. As shown in the equation, eq. (2) contains no TSC peak coordinates. Three coordinate points on the TSC spectrum, noted as $a\left(T_{a}, I_{a}\right), b\left(T_{b}, I_{b}\right)$ and $c\left(T_{c}, I_{c}\right)$ as shown in Fig. 3 are used for an application of AEM- $v$.This equation, therefore, made possible not only the evaluation of $v$ value from a TSC spectrum without a maximum peak, but also the continuous determination of $v$ values from any point on a TSC spectrum.

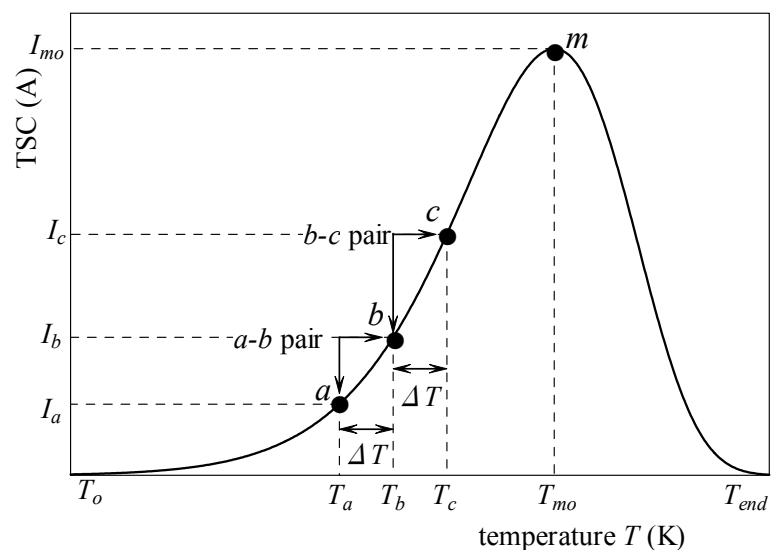

Fig. 3. Coordinate on the TSC spectrum of the AEM- $v$.

Although two pairs of data points from a TSC spectrum are required for AEM- $v$, at least three points satisfy the requirement by using one point in common for both pairs. The convenient method to select data by its temperature coordinate, is shown in Fig. 3. In the method, named "moving coordinates method", two pair $(a-b$ and $b-c)$ of points at a same temperature separation $(\Delta T)$, as shown in Fig.3, is selected, holding a point at temperature $\left(T_{\mathrm{b}}\right)$ in common and inputting their coordinates into the calculation. The $E_{\mathrm{t}}$ and $v$ values at 
the intermediate temperature $\left(T_{\mathrm{b}}\right)$ are evaluated. In other words, for a calculation of $v$ value, $E_{\mathrm{t}}$ value which assumed and $a$-bpair are given in eq.(2). The same calculation is carried out to the other b-c pair at the same time. As a result, it is converged by a computer until $v$ value which calculated in both pairs becomes the same value. Numbers of the $E_{\mathrm{t}}$ and $v$ values were calculated for the coordinates of two pairs of points with $\Delta T=0.2 \mathrm{~K}$ interval, shifting by $0.2(\mathrm{~K})$ for higher values and plotted continuously on $T_{\mathrm{b}}$. As the results, this smaller temperature interval of data provides more sensitivity to detect a composite TSC objective.

Three characteristics of AEM-v are shown in Fig. 4. These characteristics applied to a single relaxation TSC theory spectrum of Fig.3. Then, it can calculate the peak temperature $T_{\mathrm{m}}$ of TSC spectrum of to be shown in Fig.4(c) from an $E_{\mathrm{t}}$ and $v$ values at the same temperature T. The part of flat shape means that a target TSC spectrum is caused by single relaxation. The values of three parameters were estimated from the means of the vertical axis of the temperature range indicating the flat shape. It can be understood that the flat shapes of the characteristics in the temperature region of the whole TSC spectrum indicate the signal to be caused by a single trap. Naturally, this peak temperature $T_{\mathrm{m}}$ is temperature indicating the maximum current $I_{m o}$ of the TSC spectrum of Fig. 3.

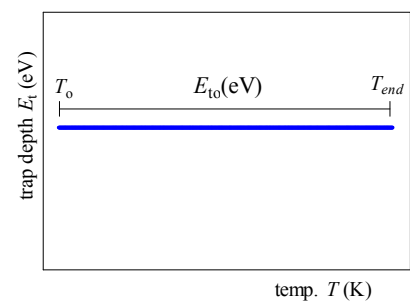

(a) $E_{\mathrm{t}}-T$ characteristic

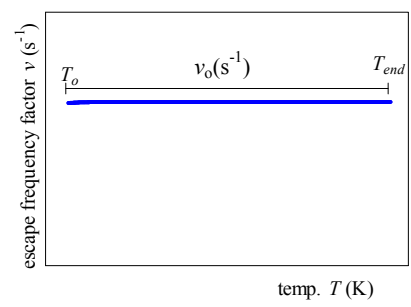

(b) $v$ - $T$ characteristic



(c) $T_{\mathrm{m}}-T$ characteristic

Fig. 4. Three characteristics of AEM- $v$ which applied to the TSC spectrum of the single trap.

The thermal cleaning method and partial heating are known as experimental separation methods of composite TSC spectrum and only initial rising part of TSC spectrum was used for estimation of $E_{\mathrm{t}}$ value. The initial rise method(Garlick \& Gibson,1948) is the only one procedure to apply to data without a peak until now. However, in AEM-v, an application is possible to an omniformity-shaped TSC spectrum.

The initial rising (signal from $T_{\mathrm{o}}$ to $T_{\mathrm{S}}$ ) part of a TSC spectrum calculated with arbitrary coefficients $\left(E_{\mathrm{to}}, T_{\mathrm{mo}}\right.$ and $\left.I_{\mathrm{mo}}\right)$ was shown in Fig. 5. The attached map of Fig. 5 is an application result of AEM- $v$. $E_{\mathrm{t}}$ and $v$ values were evaluated by the AEM-v from a part of a TSC spectrum or that without a maximum using three coordinates for the first time. Furthermore, it can be understood that the detection of the peak temperature $T_{\mathrm{m}}$ is possible from the initial part of a TSC spectrum.

The maximum coordinate of TSC spectrum and $E_{\mathrm{t}}$ value is necessary to calculate a theoretical TSC spectrum. In other word, among the maximum coordinate $m$ of TSC spectrum, maximum current $I_{\mathrm{m}}$ is required. AEM- $I$ (Yoshida et al.,1991) which we proposed can calculate maximum current $I_{\mathrm{m}}$ of the TSC spectrum as well as an evaluation of $E_{\mathrm{t}}$ values. It need a maximum temperature $T_{\mathrm{m}}$ in addition to two points, $a$ point and $b$ on the TSC spectrum which were shown in Fig.3 The basic formula of AEM-I is given in the next expression. 


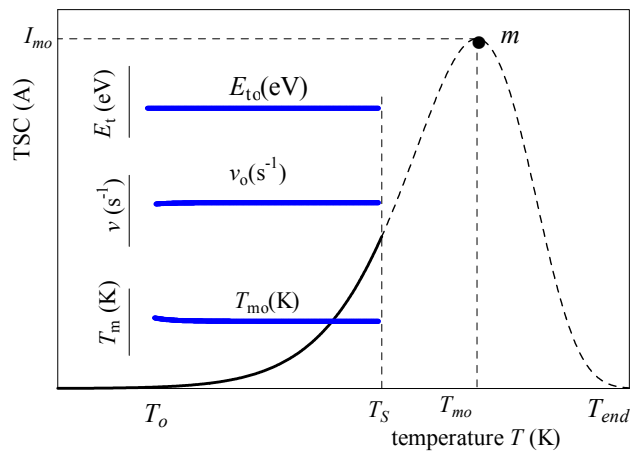

Fig. 5. Three characteristics of AEM- $v$ which applied to the initial rising part of TSC spectrum.

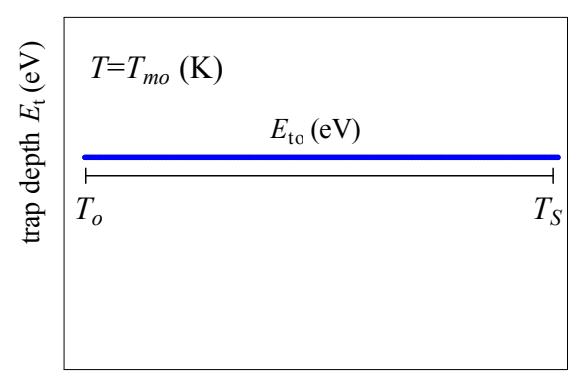

temp. $T(\mathrm{~K})$

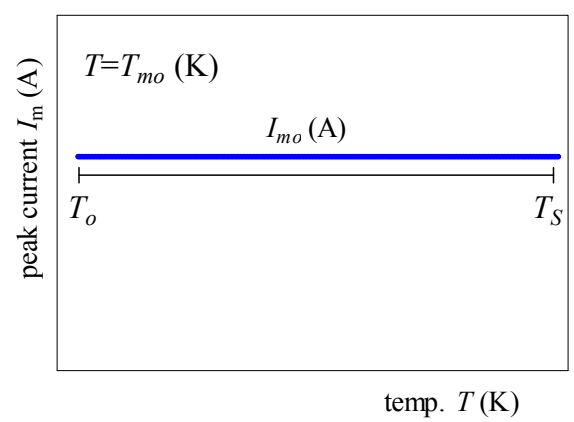

(b) $E_{\mathrm{t}}-T$ characteristic

Fig. 6. A result of having applied AEM-I to TSC spectrum of Fig.5.

$I_{\mathrm{m}}$ was calculated with two coordinate of a TSC spectrum and $T_{\mathrm{m}}$ obtained from AEM- $v$. Two characteristics of AEM-I were presented in Fig. 6. Like Fig. 5, the flat shape means the signal was detected from a single trap. It was able to evaluate maximum coordinate and trap depth $E_{\mathrm{t}}$ of the TSC spectrum by AEM- $v$ and AEM-I. As a result, the calculation of the TSC theoretical spectrum is enabled and is shown with a dashed line in Fig. 5. In AEMs, the reconstruction of the whole TSC spectrum is possible from the part of the TSC observed in this way.

$$
\begin{gathered}
A_{I}=-\ln \frac{I_{a}}{I_{b}}+\left(\frac{T_{b}}{T_{m}}\right)^{2}\left[\sum_{n=0}(-1)^{n} \frac{(n+1) !}{\left(\frac{A_{I} T_{a}}{T_{b}-T_{a}}\right)^{n}} \exp \left\{\frac{A_{I} T_{a}\left(T_{b}-T_{m}\right)}{T_{m}\left(T_{b}-T_{a}\right)}\right\}\left\{1-\left(\frac{T_{a}}{T_{b}}\right)^{n+2} \exp \left(-A_{I}\right)\right\}\right] \\
E_{\mathrm{t}}=A_{I} \frac{k T_{b} T_{a}}{T_{b}-T_{a}}
\end{gathered}
$$

\subsection{AEM separation system}

AEM- $v$ can do a judgment whether or not the contribution of the trap is single. The merit of AEM- $v$ is enabled the separation of a compound TSC spectrum without thermal cleaning 
measurements. We name "AEM separation system" as this separation method and carry it out by computerization.

Then, we explain the procedure of this separation method using the calculated TSC spectrums. A separation object is a compound TSC spectrum formed of two traps.

At first the TSC spectrum is screened by AEM- $v$. Then, the observed TSC spectrum can visualize by the information from a trap. Because both peaks $\left(P_{1}\right.$ and $\left.P_{2}\right)$ are exposed, Fig.7 shows that it is the signal from two traps ( $C_{1}$ peak to show in Fig.10 and $C_{2}$ peak) easily.

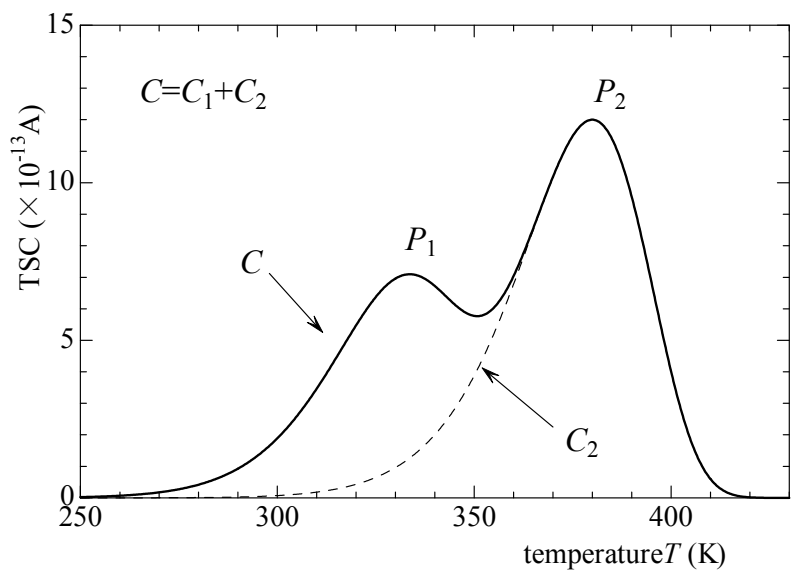

$C_{1}$ curve: $E_{\mathrm{to}, 1}=0.570(\mathrm{eV}), T_{\mathrm{mo} .1}=330.00(\mathrm{~K}), I_{\mathrm{mo}, 1}=6.000\left(\times 10^{-13} \mathrm{~A}\right)$

$C_{2}$ curve $: E_{\mathrm{to}, 2}=0.740(\mathrm{eV}), T_{\mathrm{mo} .2}=380.00(\mathrm{~K}), I_{\mathrm{mo}, 2}=12.00\left(\times 10^{-13} \mathrm{~A}\right)$

Fig. 7. Compound TSC spectrum consisting of two traps.

Figure 8 is the result that is applied AEM- $v$ to a compound TSC spectrum of Fig. 7. An abscissa of Fig.8 is the temperature region that used in calculation. Figure 8(a) and (b) are trap depth $E_{\mathrm{t}}$ and escape frequency factor $v$ respectively. A flat part is the temperature region that is strong in the contribution of the single trap. This $E_{\mathrm{t}}-T$ characteristic can evaluate $E_{\mathrm{t}}$ values of $0.570 \mathrm{eV}$ and $0.740 \mathrm{eV}$. In particular, the large flat part of $T_{\mathrm{m}}-T$ characteristic (Fig.8(c)) leads to a $T_{\mathrm{m}}$ value. The big divergence of the neighborhood of $350 \mathrm{~K}$ expresses the place that is strong in contribution of the combined signal. Then, using provided $T_{\mathrm{m}}=380.00(\mathrm{~K})$, AEM- $I$ is applied.



(a) $E_{\mathrm{t}}-T$ characteristic

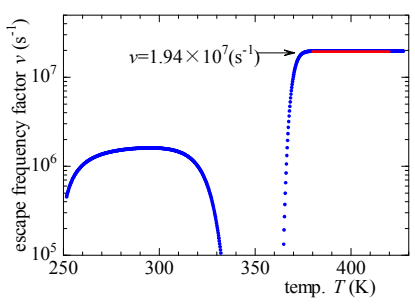

(b) $v$ - $T$ characteristic

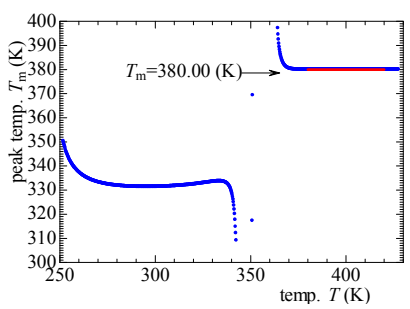

(c) $T_{\mathrm{m}}-T$ characteristic

Fig. 8. Three characteristics that applied AEM- $v$ to Fig.7. 


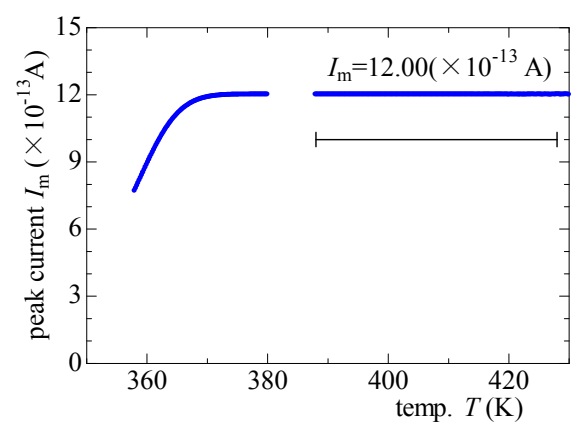

(a) $I_{\mathrm{m}}-T$ characteristic

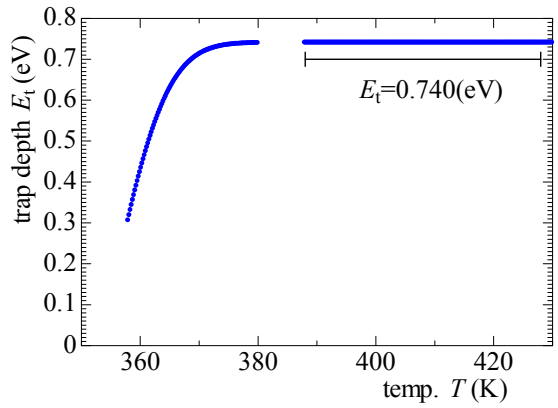

(b) $E_{\mathrm{t}}-T$ characteristic

Fig. 9. As a result of having applied AEM-I to the $P_{2}$ peak of Fig.7.

Figure 9 is two characteristics of AEM- $I$ which applied to $P_{2}$ peak of Fig.7 to target separation. $I_{\mathrm{m}}$ value is found from a flat part of Fig. 9(a). In this case, an $E_{\mathrm{t}}$ value is found by a flat part of Fig.9(b) or Fig. 8(a). When the maximum coordinate of the TSC spectrum is exposed, AEM-LH (Maeta \& Sakaguchi,1980;Maeta \& Yoshida,1989)is applicable. And AEM- $L H$ enables an evaluation of trap depth $E_{\mathrm{t}}$ again, too. At this stage, the AEM separation system fine-tunes the maximum coordinate of the TSC spectrum to raise the flat shape of $E_{t^{-}}$ $T$ characteristic more fine. The $C_{2}$ curve of Fig.7 calculated using maximum coordinate $(380.00,12.00)$ and $E_{\mathrm{t}}(0.740 \mathrm{eV})$ which were detected.

It is the newly exposed TSC spectrum ( $C_{1}$ curve) which deduct $C_{2}$ curve from $C$ curve targeted for separation in Fig. 10. Figure 11 shows the result that applied AEM-I to $C_{1}$ curve. Here, AEM- $I$ was applied after determination of the peak temperature $T_{\mathrm{m}}(330.00 \mathrm{~K})$ by AEM- $v$. Because two characteristics show flat in all temperature region, this $C_{1}$ curve understands that it is the signal caused by a single trap.

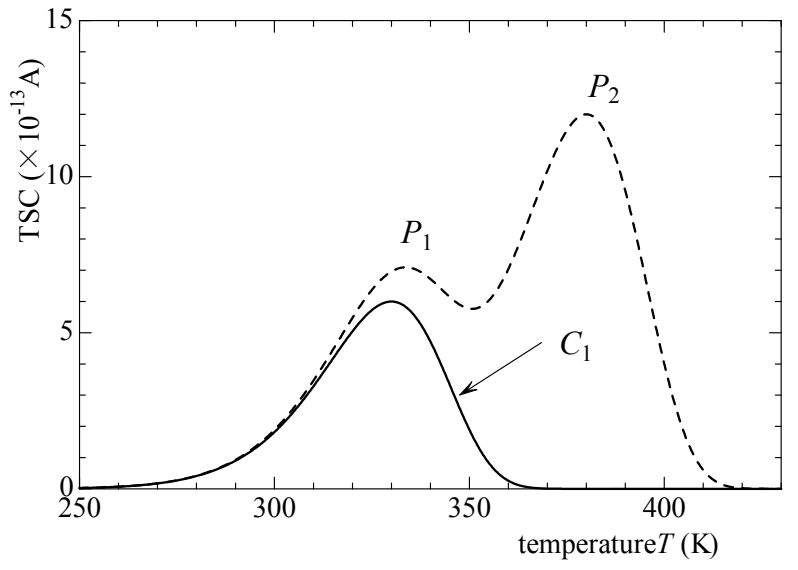

Fig. 10. The $C_{1}$ curve exposed from a compound TSC spectrum. 


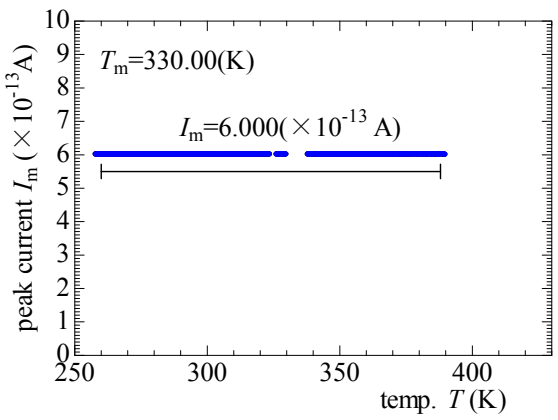

(a) $I_{\mathrm{m}}-T$ characteristic

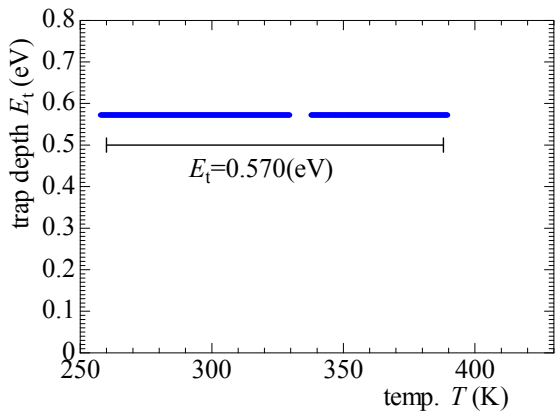

(b) $E_{\mathrm{t}}-T$ characteristic

Fig. 11. The result that applied AEM-I to $C_{1}$ curve in Fig.10.

Figure 12 is an example looking like a single TSC spectrum in an appearance.

Contribution of trap signal ( $C^{\prime}$ curve) is closer than a compound TSC spectrum of Fig. 7. Figure 13 shows the result that applied AEM separation system to Fig. 12.

Three characteristics detect a $C^{\prime}$ curve is compound contribution in high sensitivity.

This result can evaluate $E_{\mathrm{t}}$ of the outline as $0.740 \mathrm{eV}$ directly even if do not separate a TSC spectrum. If a flat part can be detected on a TSC spectrum, the separation is possible.

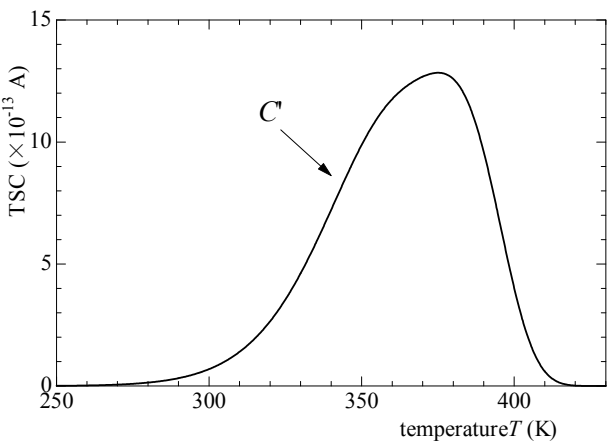

Fig. 12. An example of the TSC spectrum of strong multiplicity.

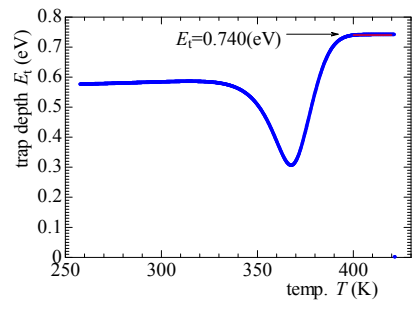

(a) $E_{\mathrm{t}}-T$ characteristic



(b) $v$ - $T$ characteristic

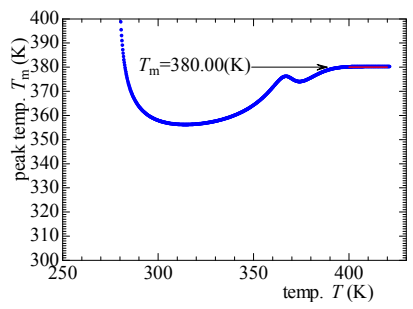

(c) $T_{\mathrm{m}}-T$ characteristic

Fig. 13. Three characteristics that applied AEM- $v$ to Fig.12. 


\section{Experimental results}

\subsection{Grid voltage dependence of the surface potential}

Figure 14 is surface potential $V_{\mathrm{s}}$ properties of three kinds of PP when changed the grid voltage $V_{\mathrm{g}}$. The needle voltage $V_{\mathrm{N}}$ is fixed at each $\pm 3 \mathrm{kV}$. The corona discharge condition is charging time $t_{\mathrm{d}} 60 \mathrm{~s}$ at room temperature under $1 \mathrm{~atm}$. In positive corona charge, the maximum charged potential became ca. $1.1 \mathrm{kV}$ and ca.1.25kV each in PP1 and PP2. And PP3 of the porous PP film became ca.1.47kV. On the other hand, as for the negative corona charge, PP1 and PP2 became ca.-300V and ca.-690V each, and PP3 became ca.-820V. This result shows that charged surface potential of the positive corona charge is high in all film. This accords with a report that PP of the contact charging is easy to be charged with electricity in a plus.

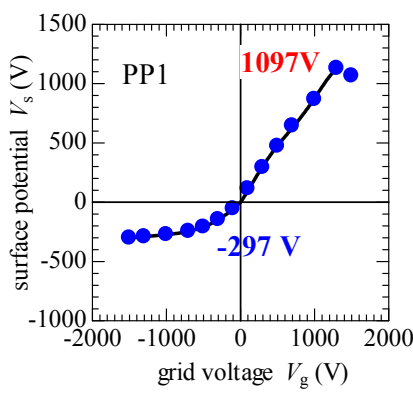

(a) PP1 film



(b) PP2 film

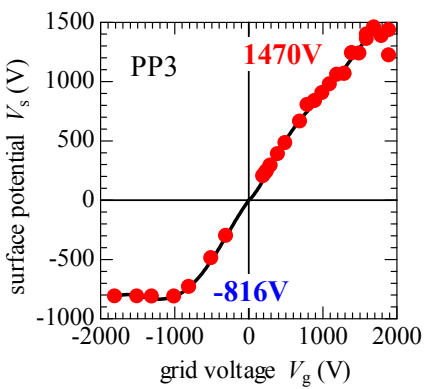

(c)PP3 film

Fig. 14. Grid voltage dependence of the surface potential.

Figure 15 showed Fig.14 in a mass. It is revealed that clear saturation happens in surface potential by the negative corona charge. On the other hand, for positive corona charge, the surface potential shows linear charging characteristics to ca. $1 \mathrm{kV}$ of the grid voltage.

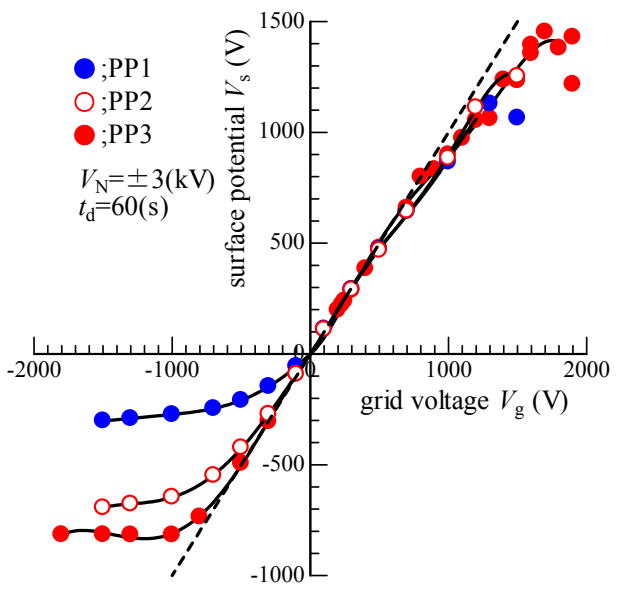

Fig. 15. Comparison of three kinds of PP films. 


\subsection{Isothermal potential decay}

Isothermal decay of the surface potentials were measured during $10^{4} \mathrm{~s}$ as shown in Fig.16. Each characteristic standardized it in surface potential $V_{\text {so }}$ at the time of the start of measurement. In positive corona charge, PP1 and PP2 of the solid film are quick in decay, and the decay of ca. $4 \%$ of initial values is seen in progress for $3 \mathrm{~h}$. However, decay is not seen for the negative corona charge. In contrast, even if PP3 passes for $3 \mathrm{~h}$, it holds initial potential. In positive corona charge, Time constant of the decay for PP1,PP2 and PP3 were revealed to be $121 \mathrm{~h}, 161 \mathrm{~h}$ and $806 \mathrm{~h}$, respectively.

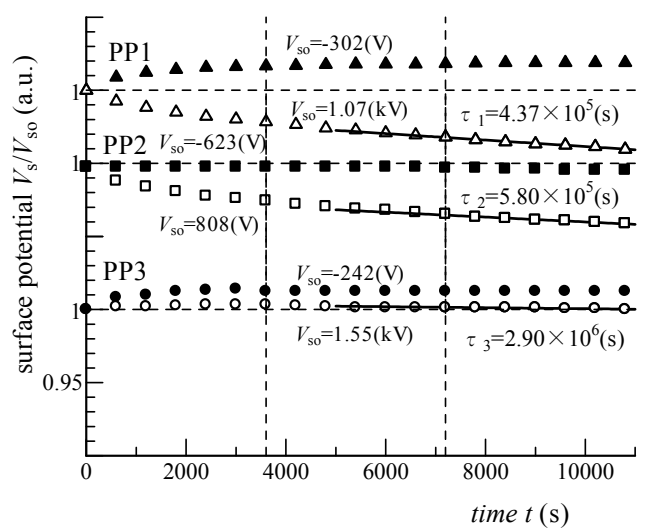

Fig. 16. Isothermal surface potential decay curves for porous and solid PP films at room

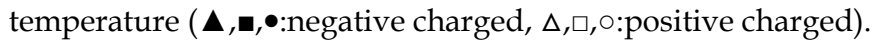

\subsection{Thermally stimulated charge decay}

In generally, temperature condition is important factor in examining the electric-electronic industry material. Therefore, the next performed thermally stimulated charge decay (TSCD) experiment of the PP films. In Fig.17, TSCD characteristics from positively charged PP films were presented. Charge decay of PP1 and PP2 occurred around 390K and 280K, respectively, although PP3 released the charge above 410K. At 430K, PP1, PP2, and PP3 lost $20 \%, 78 \%$, and $7 \%$ of initial surface potential $V_{\text {so, }}$ respectively.

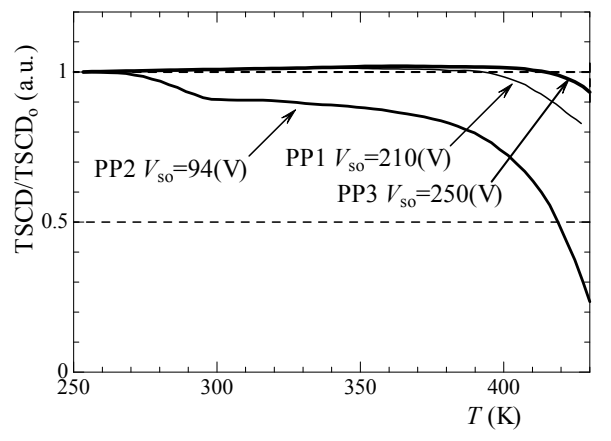

Fig. 17. TSCD characteristics from positively corona charged PP films. 


\subsection{Thermally stimulated current}

The sample which used by TSCD experiment has a TSC experiment successively without exposing a sample to air from a good point of the measuring apparatus. As a result, because it is identical test items, both experimental results compare it directly and can analyze it precisely. TSC spectra measured for PP1, PP2, and PP3 are shown in Fig. 18(a),(b), and (c), respectively.

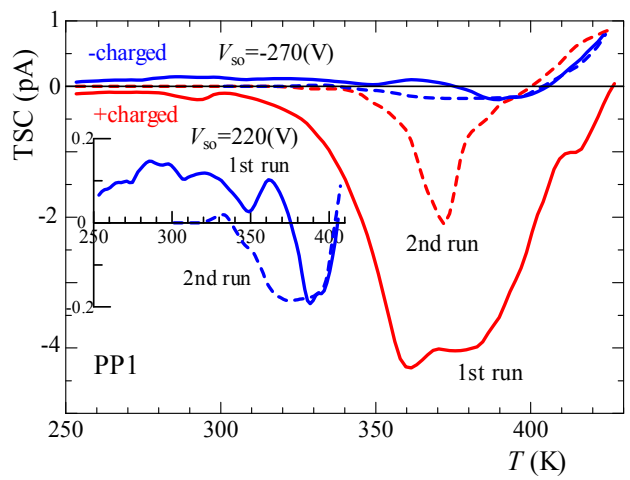

(a) PP1 film

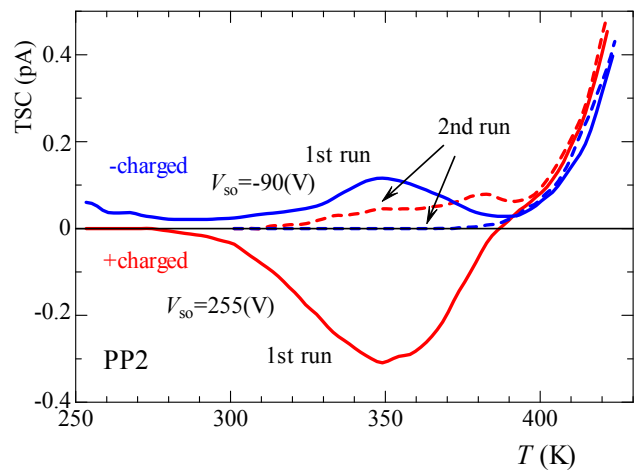

(b)PP2 film



(c)PP3 film

Fig. 18. TSC characteristics for porous PP and solid PP.

In the figures, TSC spectrum recorded after positively charged was presented by red line, beside that after negatively charge was shown by blue line. Solid line represented TSC recorded during initial heating after being charged, though the second heating that performed without charging after the film was rapidly frozen caused TSC spectrum shown by dashed line. The attached map in Fig. 18(a) shows an enlarged picture of negative charged TSC spectrum. A plurality of TSC peaks are observed in a temperature region $375 \mathrm{~K}$ from $250 \mathrm{~K}$. It was shown that the magnitude of TSC signals in the base polymer, PP1, charged positively were larger than that charged negatively. The TSC spectrum of PP3 is observed with each charge polarity in ca.370K and ca.375K. In each sample, signal detected in the second run clearly decreased. In every case, however, the increasing current was 
observed about $400 \mathrm{~K}$. As a result of Blank experiment, we regard the increase current at high temperature as a thing by the thermolysis ion.

\section{Separation of the actual survey TSC spectrum}

Generally, as for the observed TSC, the single trap contribution is rare, and a plurality of signal overlaps in most actual survey TSC spectra thermally. Many insulating materials are easy to catch the temperature distortion from the badness of conduction of heat. In other word, this cannot ignore the influence that a heat cycle history gives a sample. This has been regarded as a cause to disturb an accurate evaluation. The solution must separate the signal contribution of the trap from one TSC measurement. This can be settled by the AEM separation system which it described in Chapter 3. In addition, the AEM separation system can separate thermal noise and the residual current by other causes in a separation process. This chapter uses the actual survey TSC spectrum of Fig.18(b) for an example and explains a separation process.

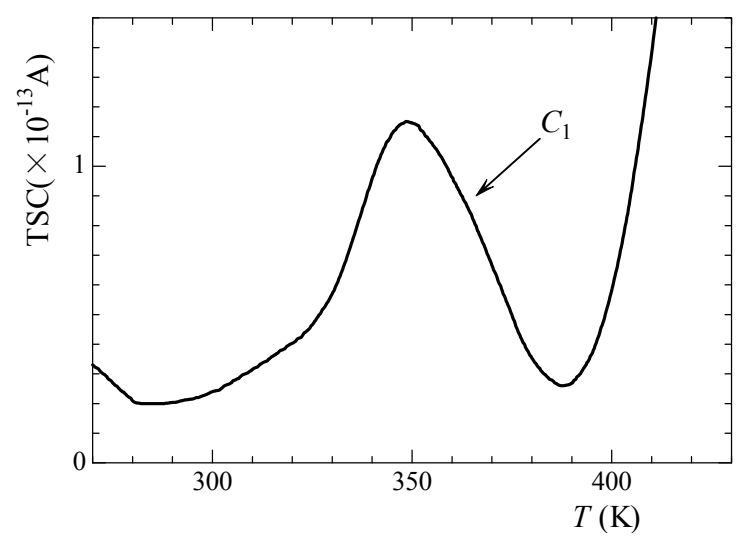

Fig. 19. An example of a TSC spectrum targeted for separation.

Figure 19 is a TSC spectrum targeted for separation and shows the each characteristic in Fig. 20. The maximum coordinate of the TSC spectrum is provided by pushing forward AEM-I and a process from AEM- $v$. And trap depth $E_{\mathrm{t}}$ evaluates it in AEM-LH. In each characteristic of Fig.20, temperature region that seems to be contributed from a single trap was estimated. Using TSC maximum coordinate $\left(349.00 \mathrm{~K}, 1.150 \times 10^{-13} \mathrm{~A}\right)$ and trap depth $E_{\mathrm{t}}(0.764 \mathrm{eV})$ decided by the screening of the TSC spectrum, $P_{\mathrm{m}}$ peak of Fig. 21(a) was calculated by eq. (1). Figure 21 shows the temporary separation of the TSC spectrum. The $C_{2}$ curve of Fig.21(a) is the resultant curve of removal of a $P_{\mathrm{m}}$ peak from actual survey TSC spectrum $C_{1}$. Figure $21(b)$ is the result of application of AEM- $L H$ to $C_{2}$ curve. At the stage, the maximum of the TSC spectrum is revealed. And the TSC spectrum which was calculated using this TSC maximum coordinate and trap depth $E_{\mathrm{t}}$ results the $P_{\mathrm{h}}$ peak of Fig. 21(c). The $C_{3}$ curve is obtained by removal of $P_{\mathrm{h}}$ peak from $C_{2}$ curve. The minus current of the neighborhood of $350 \mathrm{~K}$ of the $C_{3}$ curve shows that $P_{\mathrm{h}}$ peak and agreement of the $C_{2}$ curve are incomplete. Therefore it is necessary to revise a $P_{\mathrm{m}}$ peak. 


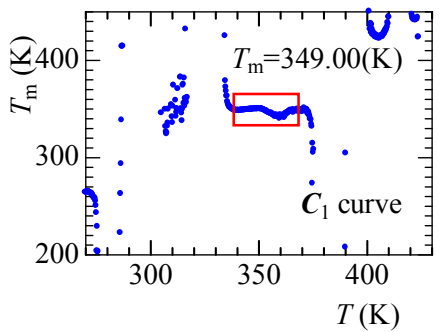

(a) $T_{\mathrm{m}}-T$ characteristic from AEM- $v$

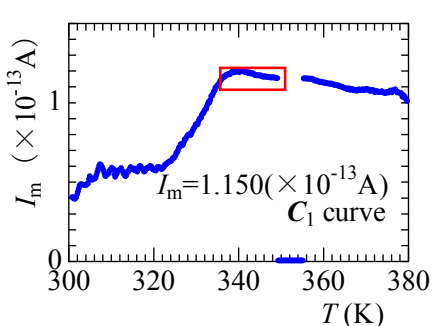

(b) $I_{\mathrm{m}}-T$ characteristic from AEM-I

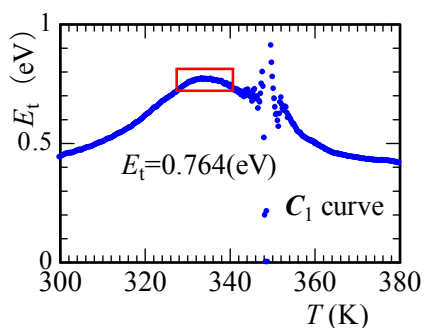

(c) $E_{\mathrm{t}}-T$ characteristic from AEM- $\mathrm{LH}$

Each evaluation is averaged in a part surrounded with the square of each part.

Fig. 20. Characteristic from each AEM of Fig.19.

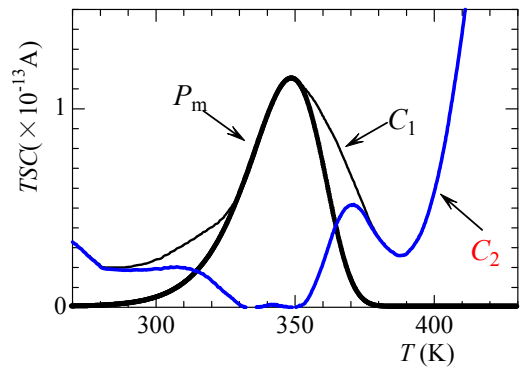

(a) Calculation of the $P_{\mathrm{m}}$ peak

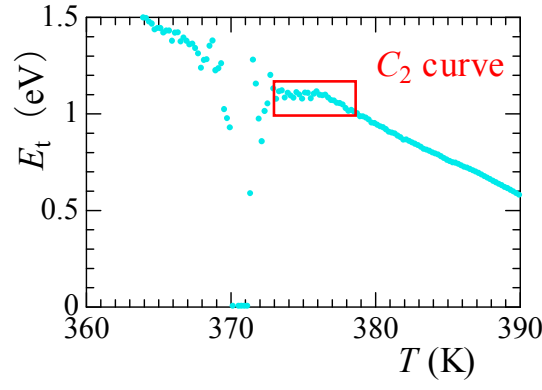

(b) $E_{\mathrm{t}}-T$ characteristic of the $C_{2}$ curve

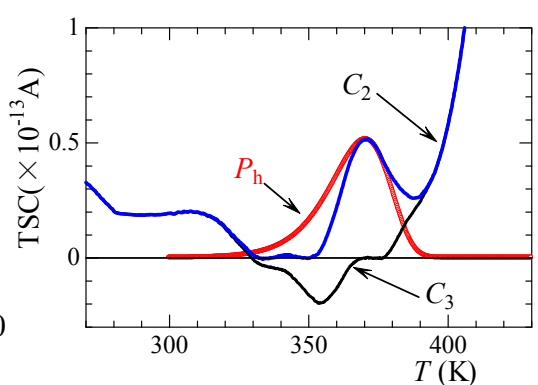

(c) Calculation of the $P_{\mathrm{h}}$ peak

Fig. 21. Temporary separation process of the TSC spectrum. 
Figure 22 is a revision process of the $P_{\mathrm{m}}$ peak. The $C_{4}$ curve of Fig. 22(a) is obtained by removal of $P_{\mathrm{h}}$ peak from $C_{1}$ curve. The $E_{\mathrm{t}}-T$ characteristic of the $C_{4}$ curve become Fig.22(b). The $P_{\text {mo }}$ peak of Fig.22(c) is the result that $P_{\mathrm{m}}$ peak was revised using an $E_{\mathrm{t}}$ value of Fig.22(b) and the maximum of the TSC spectrum. The $P_{\text {mo }}$ peak is the TSC signal which decided. Furthermore, Fig.23 shows the revision process of the $P_{\mathrm{h}}$ peak. The $C_{5}$ curve of Fig. 23(a) is obtained by removal of $P_{\text {mo }}$ peak from actual survey TSC spectrum $C_{1}$. The $E_{\mathrm{t}}-T$ characteristic of the $C_{5}$ curve become Fig.23(b). The $P_{\text {ho }}$ peak of Fig.23(c) becomes the correction curve of the $P_{\mathrm{h}}$ peak. $P_{\text {ho }}$ peak accord with actual survey TSC spectrum $C_{2}$ well in comparison with $P_{\mathrm{h}}$ peak of Fig.21(c).The AEM separation system repeats such a calculation process in all temperature region of the measured TSC spectrum. Figure 24 is TSC signal and the residual current $C_{\mathrm{r}}$ that were finally decided.

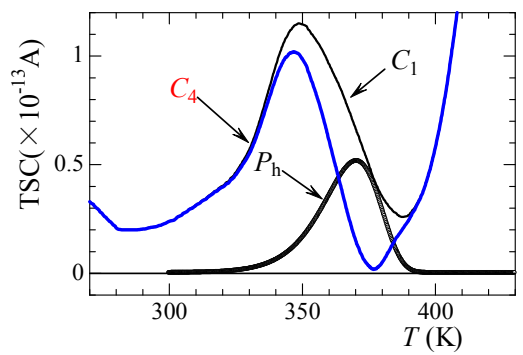

(a) $C_{4}$ curve of an exposed low temperature side TSC spectrum

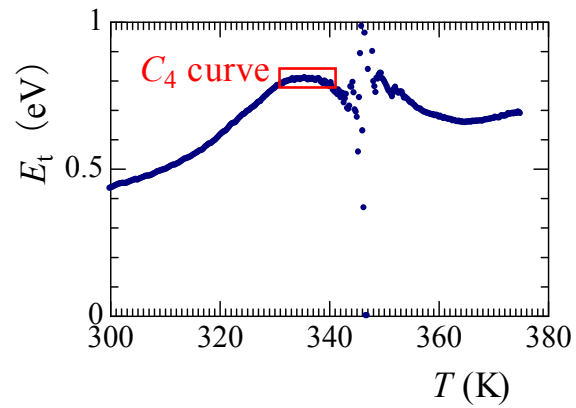

(b) $E_{\mathrm{t}}-T$ characteristic of the $C_{4}$ curve

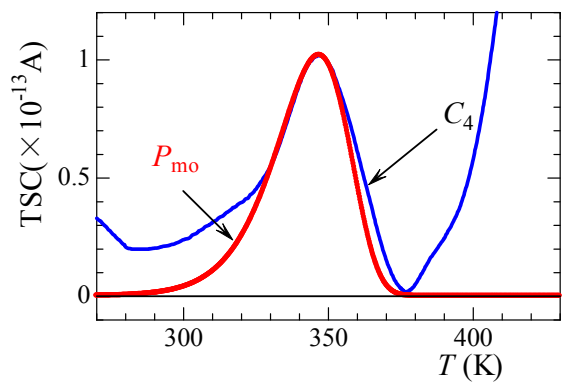

(c)The actual survey TSC spectrum which corrected at $P_{\mathrm{h}}$ peak

Fig. 22. Revision separation process of the TSC spectrum. 


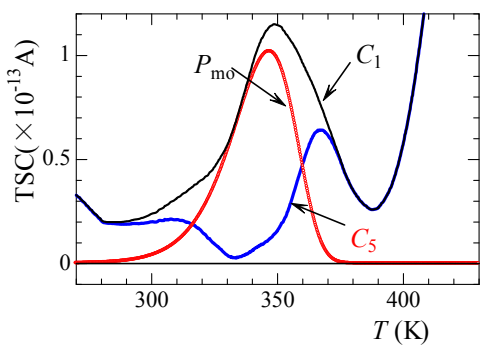

(a) The high temperature side TSC spectrum which was corrected

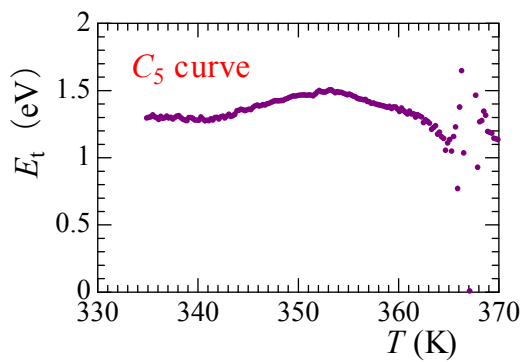

(b) $E_{\mathrm{t}}-T$ characteristic of the $C_{5}$ curve

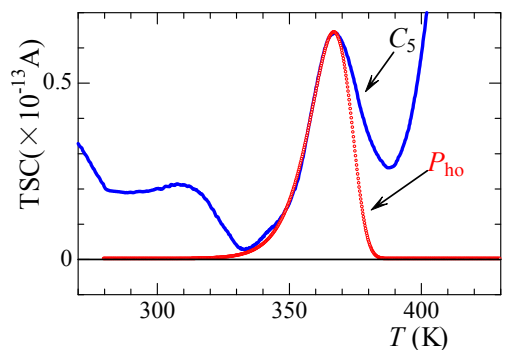

(c) The actual survey TSC spectrum which corrected at $P_{\text {mo }}$ peak

Fig. 23. Revision separation process of the TSC spectrum.

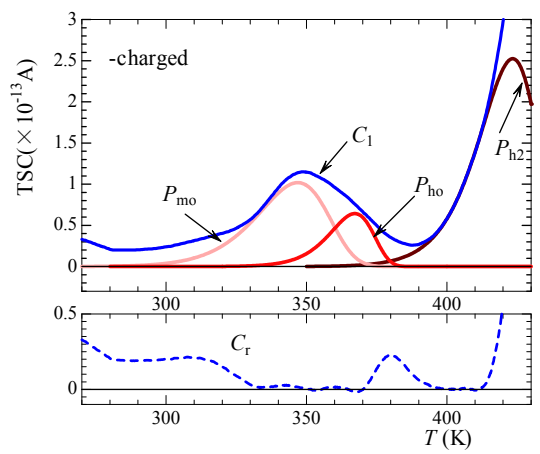

Fig. 24. TSC spectrum separation result of the negative corona charge of the PP2 film. 


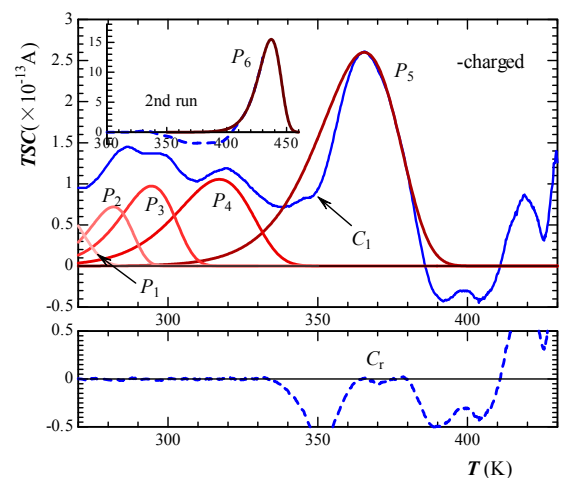

a) negative corona charge

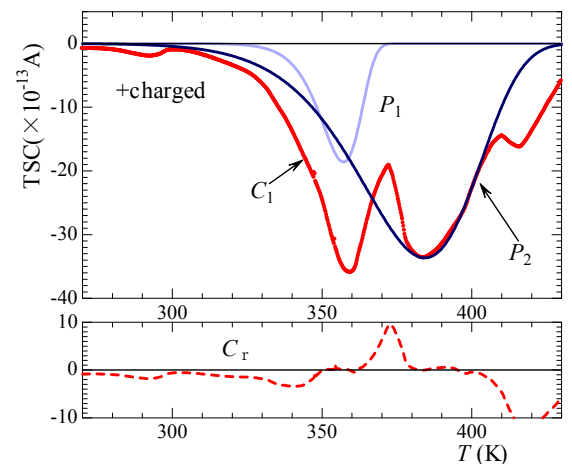

(b) positive corona charge

Fig. 25. Separation result of PP1 film.

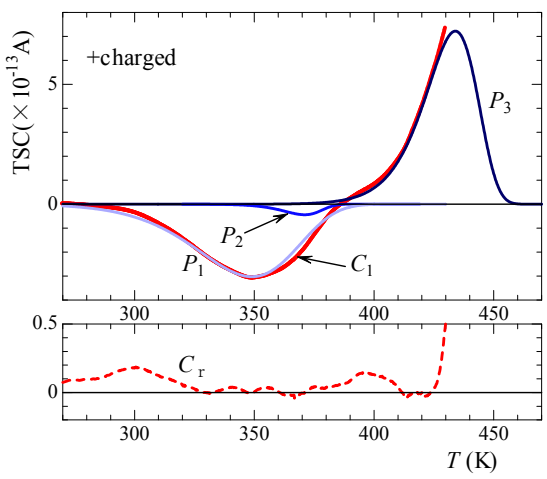

Fig. 26. Separation result of PP2 film due to the positive corona charge.

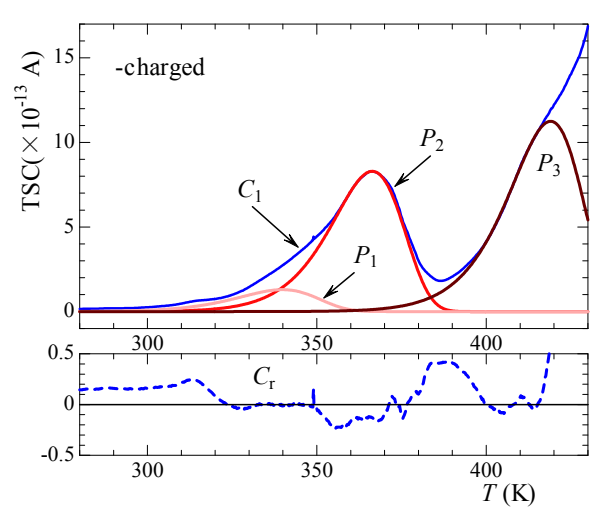

(a) negative corona charge

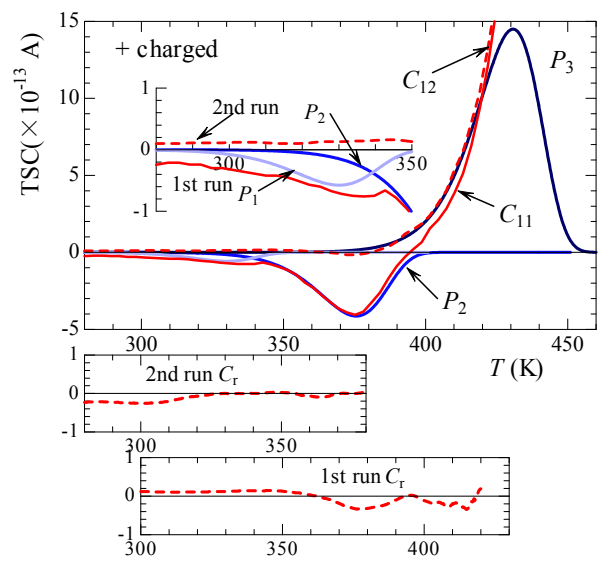

(b) positive corona charge

Fig. 27. Separation result of PP3 film. 
Figure 25-27 are the result that separated a TSC spectrum of three kinds of PP film. In Fig. 25(a) are negative corona charge, Fig. 25(b) are positive corona charge. The residual current $C_{\mathrm{r}}$ after the separation spreads and displays it.

The negative corona charge TSC spectrum was separated at the peaks from $P_{1}$ to $P_{6}$. Actual survey TSC spectrum $C_{1}$ deducts 2 nd run TSC and removes the increase current of high temperature region. $P_{5}$ peak accords with the high temperature side of the maximum peak of the $C_{1}$ curve well, but understand that $C_{1}$ curve is distorted in the low temperature side. Because the low temperature side of the $C_{1}$ curve accords with a temperature region of inversion current observed in 2 nd run TSC, it is considered as influence. The $P_{6}$ peak to show in attached map is a separation result of the 2 nd run TSC.

On the other hand, in the case of positive corona charge, actual survey TSC spectrum $C_{1}$ was separated by two TSC spectra (a $P_{1}$ peak and $P_{2}$ peak). A $P_{2}$ peak and the disagreement in the neighborhood of $370 \mathrm{~K}$ of $C_{1}$ curve are regarded as the influence of a peak observed in the neighborhood of $370 \mathrm{~K}$ of the 2nd run TSC to show in Fig. 18(a).

Then, a result of the PP2 film is shown in the Fig. 26. In the case of negative corona charge, we already showed it at a point of the explanation of the separation process of Chaper 5 . For the positive corona charge, the $C_{1}$ curve was separated at three peaks from $P_{1}$ to $P_{3}$. The $P_{3}$ peak is the reconstruction of the TSC spectrum from the actual survey $C_{1}$ spectrum only for the initial rising part that it explained by AEM- $v$ theory.

Finally Fig. 27 is a separation result of PP3 film. In the 2nd run TSC, the main peaks less than $400 \mathrm{~K}$ are cleaned. In negative and positive corona charge, it was divided into the TSC spectrum from three traps. The $P_{3}$ peak of the positive corona charge is inversion TSC separated by 2 nd run TSC ( $C_{12}$ curve). In attached map of Fig.27(b), the enlarged figure of separation result less than $350 \mathrm{~K}$ is shown. The $\mathrm{Cr}$ curve is a result expect the TSC signal.

\section{Discussions}

A signal for the contribution of the single trap must be separated to evaluate the information of the trap from the measured TSC spectrum. The information of trap to be discussed in this chapter is the result that applied all AEM separation system. Furthermore, we discuss the escape frequency factor $v$ of the trap here and mention the origin of the trap.

\subsection{Trap depth $E_{\mathrm{t}}$ and observation temperature $T_{\mathrm{m}}$}

The trap depth $E_{\mathrm{t}}$ values of the TSC signals separated are plotted to the peak temperatures $T_{\mathrm{m}}$ as are shown in Fig. 28.

Generally the trap depth is deepened so that an observed tempearature region of the TSC signal becomes the high temperature. However, the separation result does not necessarily behave like that. The origin of various traps is thought about. In PP1 film to show in Fig. 28 (a), there are four traps (from $P_{1}$ to $P_{4}$ peak) from about $0.59 \mathrm{eV}$ to about $0.95 \mathrm{eV}$ in less than $350 \mathrm{~K}$ for negative corona charge. And there is a trap of $0.841 \mathrm{eV}\left(\mathrm{P}_{5}\right.$ peak) by $400 \mathrm{~K}$ from $350 \mathrm{~K}$. In the case of positive corona charge, two traps $\left(1.61 \mathrm{eV}\right.$ of $P_{1}$ peak and $0.617 \mathrm{eV}$ of $P_{2}$ peak) exist in the same temperature region. Only $P_{6}$ peak $(1.77 \mathrm{eV})$ of the negative corona charge exists when it becomes than $400 \mathrm{~K}$. 


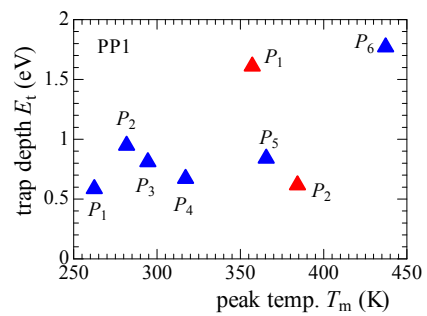

(a)PP1 film

$(\boldsymbol{\Delta}:$ +charged, $\Delta$ :-charged $)$



(b)PP2 film

( $\square:+$ charged, $\square$ :-charged)

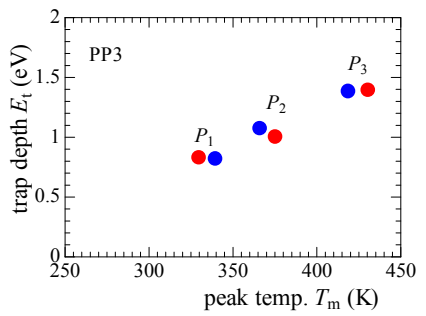

(c)PP3 film

$(\bullet:+$ charged, $\bullet$ :-charged)

Fig. 28. Correlation of trap depth $E_{\mathrm{t}}$ of three PP film.

In the case of PP2 film to show in Fig. 28(b), three traps exist in the almost same temperature region more than $350 \mathrm{~K}$ regardless of polarity of the charge. The depth trap of $P_{1}$ peak $(0.473 \mathrm{eV})$ is different from $P_{\text {mo }}$ peak $(0.801 \mathrm{eV})$ greatly. However, as for four trap $\left(P_{\mathrm{ho}}, P_{2}, P_{\mathrm{h} 2}\right.$ and $P_{3}$ peak), about $1.5 \mathrm{eV}$ is evaluated regardless of polarity of the corona charge. When PP2 film compare with PP1 film in the negative corona charge, it understands that the number of charge trapping decreases solid film two axis orients it. Furthermore, the TSC intensity of the $P_{2}$ peak of PP1 film for the positive charge is very big. As for the polymeric film which drawn, electrical specification is known to be improved. In the case the solid film has much number of the traps for negative corona charge and it is thought that space charge accumulation that a trap forms is bigger than drawn film for positive corona charge. This does not contradict it about the high insulation that drawing operation of the film gives.

Then, Fig.28(c) is a separation result of the porous film. It is understand that three discrete peaks do not depend on the corona charging polarity. In both $P_{1}$ peak, temperature regions less than $350 \mathrm{~K}$ and both $P_{2}$ peak are observed each in the temperature region of $400 \mathrm{~K}$ from $350 \mathrm{~K}$. And there is both $P_{3}$ peak in the temperature regions more than $400 \mathrm{~K}$. Trap depth $E_{\mathrm{t}}$ of each peak was evaluated as about $0.82 \mathrm{eV}-0.83 \mathrm{eV}$, about $1.0 \mathrm{eV}-1.1 \mathrm{eV}$ and about $1.4 \mathrm{eV}$ from the temperature region sequentially. Each peak regardless of polarity of corona charge understands that it is the same trap depth.

\subsection{Escape frequency factor $v$ and observation temperature $T_{\mathrm{m}}$}

Figure 29 are the result that evaluated escape frequency factor $v$ for the observation temperature $T_{\mathrm{m}}$. The $v$ value of $P_{1}-P_{5}$ peaks for negative corona charge of solid film (PP1) to show in Fig. 29(a) is about $10^{8} \mathrm{~s}^{-1}-10^{14} \mathrm{~s}^{-1}$. In particular, the $v$ value of $P_{1}$ peak for positive corona charge is high with about $10^{20} \mathrm{~s}^{-1}$. With the two axis drawing solid film (PP2) to show in Fig.29(b), $P_{\text {ho }}$ and a $v$ values of the $P_{2}$ peak are about $10^{17} \mathrm{~s}^{-1}$ and $P_{\mathrm{h} 2}$ and $P_{3}$ peak are about $10^{14}-10^{15} \mathrm{~s}^{-1}$. As for this, order of the $v$ value accords well about the observation region of each peak. In contrast, there are approximately 5 orders of differences even if $P_{\text {mo }}$ and $P_{1}$ peak are the same observation regions.

On the other hand, the $v$ values of the porous film (PP3) accord regardless of corona charge polarity well at both peaks. The $v$ value of each peak is about $10^{9}-10^{10} \mathrm{~s}^{-1}$ of the $P_{1}$ peak, about $10^{11-10^{12}} \mathrm{~s}^{-1} \mathrm{of}$ the $P_{2}$ peak and about $10^{13}-10^{14} \mathrm{~s}^{-1} \mathrm{of}$ the $P_{3}$ peak. 




(a)PP1 film

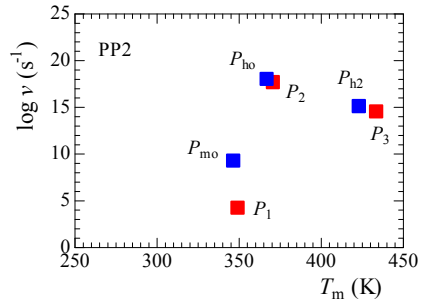

(b)PP2 film

$(\Delta:$ :charged, $\Delta$ :-charged $)$

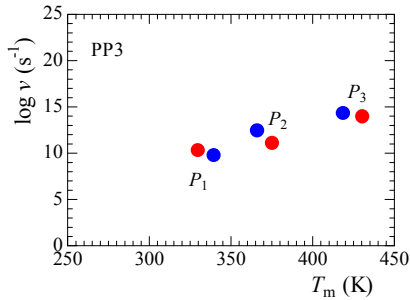

(c)PP3 film

$(\bullet:+$ charged, $\bullet$ :-charged)

Fig. 29. Correlation of escape frequency factor $v$ of three PP film.

\subsection{Magnitude of attenuation of the charged potential}

In TSC measurement, the charged potential measured twice of potential $\left(V_{\mathrm{so}}\right)$ before the start of measurement and residual potential $\left(V_{\mathrm{se}}\right)$ in the room temperature after the measurement.

\begin{tabular}{c|c|c|c|c|c}
\hline \multirow{2}{*}{ sample } & \multirow{2}{*}{ polarity } & \multicolumn{3}{|c|}{$\mathrm{TSC}$} & \\
\cline { 3 - 6 } & & $\mathrm{V}_{\mathrm{so}}(\mathrm{V})$ & $\mathrm{V}_{\mathrm{se}}(\mathrm{V})$ & $\Delta \mathrm{V}_{\mathrm{s}, \mathrm{TSC}}(\%)$ & ave. $\Delta \mathrm{V}_{\mathrm{s}, \mathrm{TSC}}(\%)$ \\
\hline \multirow{2}{*}{$\mathrm{PP} 1$} & - & -269 & -189 & -29.7 & \multirow{2}{*}{-33.4} \\
\cline { 2 - 6 } & + & 219 & 138 & -37.0 & \multirow{2}{*}{ PP2 } \\
\cline { 2 - 6 } & - & -89 & -2 & -97.8 & \multirow{2}{*}{-12.6} \\
\hline \multirow{2}{*}{ PP3 } & - & 272 & 12.6 & -95.4 & -16.5 \\
\cline { 2 - 6 } & + & -158 & -132 & -7.69 & \multirow{2}{*}{} \\
\hline
\end{tabular}

Table 2. Magnitude of attenuation of the charged potential.

Table 2 shows a result of the magnitude of attenuation of the charged potential. $\Delta V_{\mathrm{s}, \mathrm{TSC}}$ is a decrement ratio of $V_{\text {se }}$ value for the $V_{\text {so }}$ value. The ave. $\Delta V_{\mathrm{s}, \mathrm{TSC}}$ is the mean of $\Delta V_{\mathrm{s}, \mathrm{TSC}}$ value. A ave. $\Delta V_{\mathrm{s}, \mathrm{TSC}}$ value of PP1 and PP2 is about $33 \%$ and about $97 \%$ each. A value of ave. $\Delta V_{\mathrm{s}, \mathrm{TSC}}$ of the porous film is about $12 \%$. A ave. $\Delta V_{\mathrm{s}, \mathrm{TSC}}$ value of both solid film understands that two axis drawing film comes to have a bigger degree of the decrement. In the case of positive charge, the TSC experiment shows in particular a decrease in TSC strength of the two axis drawing film. As for this, the decrease in trap charges such as an electronic charge to contribute to charged potential or ionic carrier is thought about. In addition, as for the decrease in ave. $\Delta V_{\mathrm{s}, \mathrm{TSC}}$, it is thought about the property of the trap such as trap depth and the escape frequency factor having changed. The porous film has less magnitude of attenuation of ave. $\Delta V_{\mathrm{s}, \mathrm{TSC}}$ than both solid films. Seeing from a point of view of the charged retentivity of charge, the trap which a porous film forms means that it is an important factor in the retention capacity at the high temperature.

\subsection{The origin of the trap}

We discuss the correlation between trap depth $E_{\mathrm{t}}$ and the escape frequency factor $v$. In Fig.30, the data ( $v-E_{\mathrm{t}}$ correlation) of all provided traps by AEM separation system were plotted. Three domains $\mathrm{A}, \mathrm{B}$ and $\mathrm{C}$ were assumed to three peaks $P_{1}, P_{2}$ and $P_{3}$, respectively. 
Three domains are shown in the circle of dashed line in Fig.30. There is the trap formed of PP2 film in domain A and C. In the PP1 film, the trap is distributed widely other than $P_{5}$ peak in domain $\mathrm{A}$.

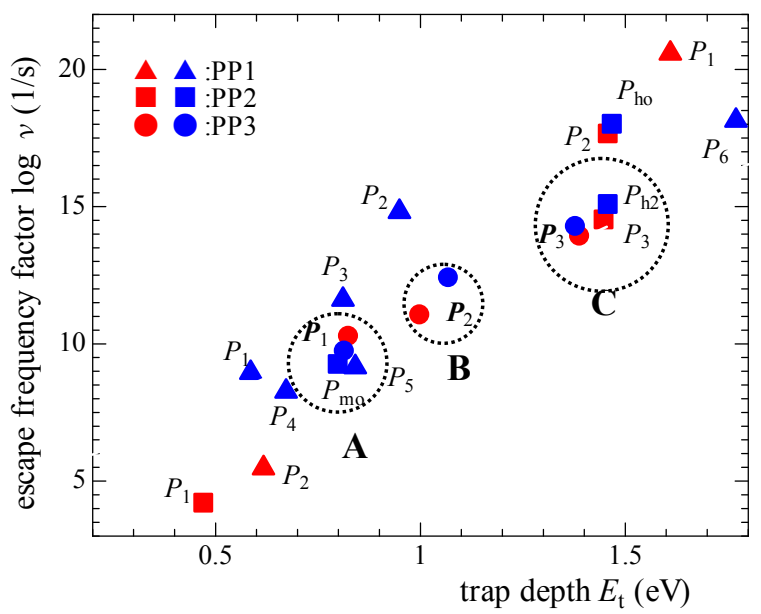

Fig. 30. Correlation of escape frequency factor $v$ and trap depth $E_{\mathrm{t}}$ of three PP film.

The difference in trap distribution of both solid films is regarded as thing by the crystallinity. Table 3 shows correlation of $v$ by $E_{\mathrm{t}}$ of three domains of the porous film. At first, the trap indicating the same correlation as in domain A of the porous film seems to be $P_{5}$ of PP1 film and the $P_{\mathrm{mo}}$ of PP2 film. Then, the trap of domain C corresponds to $P_{\mathrm{h} 2}$ and $P_{3}$ peak of PP2 film. In order word, in the origin of the trap of the $P_{1}$ peak of the porous film, even solid film is formed. And it is thought that a trap of the $P_{3}$ peak of the porous film is a trap formed two axis drawing solid film. The dramn structure of the polymer material is complicated, but traps of domain $\mathrm{A}$ and domain $\mathrm{C}$ is formed in an amorphous part and a crystal part, respectiviely. And it is thought that the trap of the porous film which there is in domain B was formed making polypropylene porous structure. It seems to be possible that this trap is formed in a pores and a boundary of the resin.

\begin{tabular}{c|c|c}
\hline Domain & $E_{\mathrm{t}}(\mathrm{eV})$ & $v\left(\mathrm{~s}^{-1}\right)$ \\
\hline $\mathrm{A}$ & $0.80-0.84$ & $10^{9}-10^{10}$ \\
\hline $\mathrm{B}$ & $1.0-1.1$ & $10^{11}-10^{12}$ \\
\hline $\mathrm{C}$ & $1.4-1.5$ & $10^{14}-10^{15}$ \\
\hline
\end{tabular}

Table 3. Three domain of the PP3 film.

There are $P_{\text {ho }}$ peak and $P_{2}$ peak formed of PP2 film in the upper part of domain C. The $E_{\mathrm{t}}$ value of both peaks is similar to domain $\mathrm{C}$, but approximately three figures of $v$ value are high. In addition, the trap of the $P_{1}$ peak of the PP2 film is located under. The trap (about $0.47 \mathrm{eV}$ ) of this $P_{1}$ peak is considerably lower than trap depth of domain A located near. As a result, it is thought that the property of the trap which PP2 film has with the same two drawing film 
reduces charging retention capacity in comparison with porous film. When this fact compares the result of the ave. $\Delta V_{\mathrm{s}, \mathrm{TSC}}$ of Table 2 and TSCD characteristics of Fig.17, it is clear.

The solid film (PP1) which lowest charged quantity, however, is higher than two axis drawn solid film (PP2) from the viewpoint of charging retention capacity in the high temperature. As for the one cause, the action of trap of the $P_{6}$ peak of the high-temperature range of the negative corona charge is thought about.

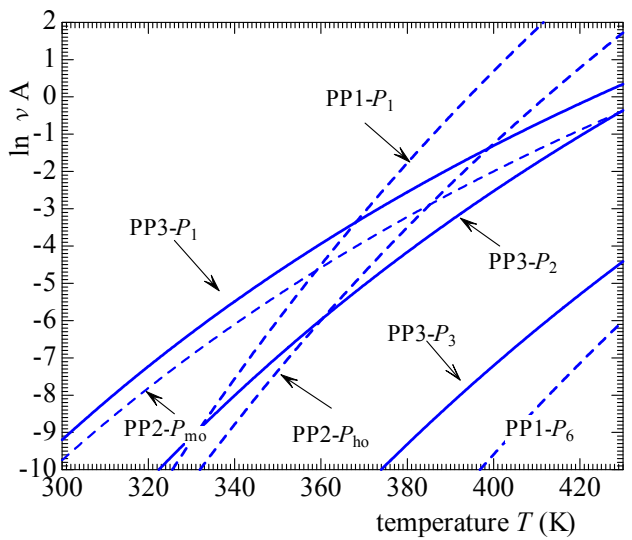

Fig. 31. A detrapping rate of the trapped carrier of the traps in the three domains.

The detrapping rates of the trapped carrier calculated in consideration of Bolzmann factor $A\left(=\exp \left(-E_{\mathrm{t}} / k T\right)\right)$ were presented in Fig. 31. The $v A$ value was calculated in negative corona charging in the observation temperature region of the TSC spectrum using evaluated $E_{\mathrm{t}}$ and v. In the figure, only a $P_{1}$ peak (PP1- $P_{1}$ ) of the PP1 film is positive corona charging. The porous film (PP3) and the solid films (PP1 and PP2) are shown with a solid line and a dashed line, respectively. From the viewpoint of charge retention at the high temperature, the $v A$ value for the temperature should be low. At first, it compares the $v A$ value of three peaks of the porous film. The $v A$ value of the $\mathrm{P}_{1}$ peak (PP3- $\left.P_{1}\right)$ is the highest of all, and those of $P_{2}$ peak (PP3- $P_{2}$ ) and the $P_{3}$ peak (PP3- $P_{3}$ ) followed in order of magnetude of $v A$ value. The detrapping characteristic of $P_{\text {mo }}$ peak (PP2- $\left.P_{\text {mo }}\right)$ of the PP2 film resombles that of PP3- $P_{1}$. The $v A$ value of $P_{\text {ho }}$ peak(PP2- $\left.P_{\text {ho }}\right)$ of the PP2 film increased more rapidly for the temperature than those of the other peaks, and it seems that this trap does not contribute to the charge retention at the high temperature. And it may be said that the $P_{1}$ peak (PP1- $P_{1}$ ) of the PP1 film of the positive corona charge is the trap which does not contribute to the charge retention at the high temperature from a reason some as the $P_{\text {ho }}$ peak. It is thought that $P_{\mathrm{h} 2}$ peak and $P_{3}$ peak of PP2 film in domain $C$ do not contribute to charge retention from a difference of the film structure with the porous film. As described above, it will be thought that the $P_{6}$ peak (PP1- $P_{6}$ )of PP1 film contributes to charge retention from the result of the $v A$ value.

On the other hand, for the positive corona charge, the trap of $P_{1}$ and the $P_{2}$ separated, could explain the result. Then trap phenomena more than $430 \mathrm{~K}$ of both corona charging are suggested when TSCD characteristics and a result of ave. $\Delta V_{\mathrm{s}, \mathrm{TSC}}$ are added. 
As a result of these, it is thought that the formation of the trap of the porous film forms it on an amorphous part and a crystal part as well as a pores and the boundary of the resin. The action of each domain is thought about as follows. It is thought that the trap of all domains takes the increase of the charged quantity. As for the piezoelectricity that a porous film has, it is thought that a trap of domain B participates. And, about the charging retention capacity of the high-temperature range, it is thought that a trap of domain $\mathrm{C}$ participates.

\section{Conclusions}

Using the polypropylene films of the solid state and the porous state, TSC measurements were performed. The next results became clear.

1. The surface potential isothermal decay for the positive corona charge maintained initial potential in the porous film in the progress for $3 \mathrm{~h}$, but was the decrement of approximately $4 \%$ with both solid films.

2. Both of solid film and porous film, as for the polypropylene, positive corona charge was higher in charged potential maximum than negative corona charge. Porous film showed the highest in the maximum charged potential.

3. From TSCD characteristics, an axis drawn solid film showed the earliest decrement of the charge potential at $430 \mathrm{~K}$. The decrement decreased sharply from temperature of about $385 \mathrm{~K}$ and, for positive corona charge, was approximately $22 \%$ of initial value. The porous film had decrement from temperature more than about $410 \mathrm{~K}$ regardless of corona charging polarity. In the porous film of the positive corona charge, decrement was caused from temperature more than about $410 \mathrm{~K}$ and, in temperature of $430 \mathrm{~K}$, maintained the potential of approximately $93 \%$.

4. As a result of having evaluated a trap by AEM separation method in a TSC spectrum, the trap of the porous film understood that it was distributed over three domains from the property.

Domain A: $E_{\mathrm{t}}: 0.80-0.84 \mathrm{eV}, v: 10^{9}-10^{10} \mathrm{~s}^{-1}$

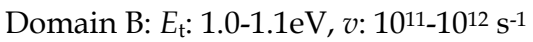

Domain C: $E_{\mathrm{t}}: 1.4-1.5 \mathrm{eV}, v: 10^{14-10^{15} \mathrm{~s}^{-1}}$

Because trap which was formed in an amorphous part because domain A existed in all film and domain B were only porous film, it was thought that it was formed in the surface boundary of a pores, and, in domain C, it was thought with the trap of a crystal part formed by extension of the film.

5. It was thought that all traps participated in charging as an action of trap which porous film formed and a trap of domain $C$ participated in the heat resistance of the charging maintenance mainly in particular. In addition, it was thought a trap of domain B acted on piezoelectricity.

\section{References}

Baba, A. \& Ikezaki, K.: "Drawing and annealing effects on thermally stimulated currents in polypropylene films",J. Appl. Phys.Vol. 72, No.5, pp.2057-2059, (1992)

Braünlich, P.: “Thermally Stimulated Relaxation in Solids”, Springer-Verlag (1979), ISBN 3540-09595-0 Springer-Verlag Berlin Heidelberg New York.

Cao, Y., Xia, Z., Li, Q., Shen, L. \& Zhou, B.: “Study of Porous Dielectrics as Electret Materials",IEEE Trans. on Dielectrics and Electrical Insulation, Vol.5, No.1,pp.5862, (1998) 
Chen, R. \& Kirsh, Y.: “Analysis of Thermally Stimulated Processes", Pergamon Press, Oxford (1981), ISBN 0080229301.

Garlick, G. F. J. \& Gibson, A. F.: “The electron trap mechanism of luminescence in sulphide and silicate phosphors", Proc. Phys. Soc.,, Vol.60, p.574, (1948)

Ikezaki, K. \& Hori, T. : "Fundamental Electric Properties of Powder-Formed Materials - Thermally Stimulated Current Spectra of Polymetic Powders - "J. Inst. Electrostatics Jpn., Vol.22, No.2, pp.79-82, (1998) [in Japanese]

Ikezaki, K. \& Murata. Y. : "Derivation of Intrinsic Thermally Stimulated Current Spectra of Polymeric Powder Samples"J. Inst. Electrostatics Jpn., Vol.30, No.1, pp.14-19, (2006) [in Japanese]

Imai, T., Hirano, Y., Kojima, S. \& Shimizu, T.: "Preparation and Properties of EpoxyOrganically Modified Layered Silicate Nanocomposites", Conf. Rec. 2002 IEEE ISEI, pp.379-383, Boston, USA (2002-4)

Ishii, K., Nagata, K., Osawa, H. \& Nanba, N.: "Piezoelectric Properties in Porous Fluoropolymer Having Isolated Voids",Trans. Inst. Electr. Eng. Jpn., Vol.129-A, No.5, pp.373-378, (2009) [in Japanese]

Ishimoto, K., Tanaka, T., Ohki, Y., Sekiguchi. Y. \& Murata, Y.: “Thermally Stimulated Current in Low-density Polyethylene/MgO Nanocomposite - On the Mechanism of its Superior Dielectric Properties -",Trans. Inst. Electr. Eng. Jpn., Vol.129-A, No.2, pp.97-102, (2009) [in Japanese]

Koga, K. \& Ohigashi, H.: "Piezoelectrisity and related properties of vinylidene fluoride and trifluoroethylene copolymers", J. Appl. Phys., Vol.59, No.6, pp.2142-2150, (1985)

Lindner, M., Bauer-Gogonea, S., Bauer, S., Paajanen, M. \& Raukola, J.: “Dielectric barrier microdischarges:Mechanism for the charging of cellular piezoelectric polymers", J. Appl. Phys., Vol.91, No.8, pp.5283-5287, (2002)

Maeta, S. \& Sakaguchi, K.: “On the Determination of Trap Depth from Thermally Stimulated Currents", Jpn. J. Appl. Phys., Vol.19, No.3, pp.519-526, (1980)

Maeta, S. \& Yoshida, F.: "On the Determination of Trap Depth from Thermally Stimulated Currents II", Jpn. J. Appl. Phys., Vol.28, No.9, pp.1712-1717, (1989)

Oka, K. \& Ikezaki, K.: "Effect of Etching Treatment on Thermally Stimulated Current in Spherulitic Polypropylene", Jpn. J. Appl. Phys., Vol.31, No.4, pp.1097-1101, (1992)

Perlman, M. M \& Creswell, R.: “Thermal Current Study of the Effect of Humidity on Charge Storage in Mylar", J. Appl. Phys., Vol.42, No.2, pp.531-533, (1971)

Varlow, B. R. \& Li, K.: "Non-linear Characteristics of Filled Resins under Alternating Field", 2002 Annu. Rep. CEIDP, pp.52-55, Cancun, Mexico (2002-10)

Xia, Z., Gerhard-Multhaupt, R., Nunstler, W. K., Wedel, A. \& Danz, R.: “High surfacecharge stability of porous polytetrafluoroethylene electret films at room and elevated temperatures", J. Phys. D: Appl. Phys., Vol.32, pp.L83-85, (1999)

Yoshida, F., Kamitani, Y., Maeta, S., Yoshiura, M. \& Ohta, T.: “Thermally Stimulated Currents in Polyaniline Film and their Analyses",Trans. Inst. Electr. Eng. Jpn., Vol.118-A, No.9, pp.1035-1042, (1998) [in Japanese]

Yoshida, F. \& Maeta, S.: "Proposal of Asymptotic Estimation $v$ Method Evaluating Escape Frequency Factor from a Partial Thermally Stimulated Current Curve Directly", Trans. Inst. Electr. Eng. Jpn., Vol.111-A, No.4, pp.323-331, (1991) [in Japanese]

Yoshida, F., Tanaka, M. \& Maeta, S.: "Proposal of Asymptotic Estimation I Method with High Sensitivity to Thermally Stimulated Current Curve and its Application to New Analysis", Trans. Inst. Electr. Eng. Jpn., Vol.111-A, No.2, pp.104-110, (1991) [in Japanese] 


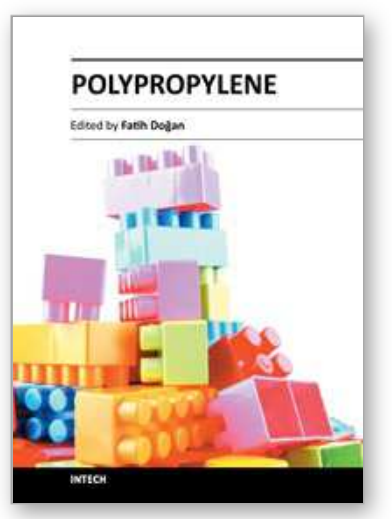

\author{
Polypropylene \\ Edited by Dr. Fatih Dogan
}

ISBN 978-953-51-0636-4

Hard cover, 500 pages

Publisher InTech

Published online 30, May, 2012

Published in print edition May, 2012

This book aims to bring together researchers and their papers on polypropylene, and to describe and illustrate the developmental stages polypropylene has gone through over the last 70 years. Besides, one can find papers not only on every application and practice of polypropylene but also on the latest polypropylene technologies. It is also intended in this compilation to present information on polypropylene in a medium readily accessible for any reader.

\title{
How to reference
}

In order to correctly reference this scholarly work, feel free to copy and paste the following:

Fukuzo Yoshida and Masahiko Yoshiura (2012). Charging Property and Charge Trap Parameters in Porous Polypropylene Film Using Thermally Stimulated Current, Polypropylene, Dr. Fatih Dogan (Ed.), ISBN: 978-95351-0636-4, InTech, Available from: http://www.intechopen.com/books/polypropylene/charging-property-andcharge-trap-parameters-in-porous-polypropylene-film-using-thermally-stimul

\section{INTECH}

open science | open minds

\author{
InTech Europe \\ University Campus STeP Ri \\ Slavka Krautzeka 83/A \\ 51000 Rijeka, Croatia \\ Phone: +385 (51) 770447 \\ Fax: +385 (51) 686166 \\ www.intechopen.com
}

\author{
InTech China \\ Unit 405, Office Block, Hotel Equatorial Shanghai \\ No.65, Yan An Road (West), Shanghai, 200040, China \\ 中国上海市延安西路65号上海国际贵都大饭店办公楼 405 单元 \\ Phone: +86-21-62489820 \\ Fax: +86-21-62489821
}


(C) 2012 The Author(s). Licensee IntechOpen. This is an open access article distributed under the terms of the Creative Commons Attribution 3.0 License, which permits unrestricted use, distribution, and reproduction in any medium, provided the original work is properly cited. 